increase (11.5\%) was seen in Edinburgh and the largest decrease (5.5\%) in Aberdeen.

Because maternal age has increased, from a mean of 26 in 1990 to 29 in 1998, ${ }^{5}$ we corrected for this variable. Breastfeeding rates were calculated in one year steps of maternal age for 1997-8. The maternal age distribution for 1990-1 was taken from the annual report of the registrar general, and breastfeeding rates for maternal age for 1997-8 were substituted into the maternal age distribution for 1990-1. The breastfeeding rate for Scotland would have been 39.4\% in 1997-8 if the maternal age distribution had been the same as in $1990-1$. Therefore, $2.6 \%$ of the observed $6.4 \%$ rise in breast feeding can be explained by increase in maternal age.

\section{Comment}

In the eight years from 1990-1 to $1997-8$, the breastfeeding rate in Scotland has increased by $6.4 \%$ from $35.6 \%$ to $42.0 \%$ at 7 days of age. Some of this increase (estimate 2.6\%) may be due to an increase in maternal age. Maternity units and health boards should be congratulated on their achievements and encouraged to increase support for breast feeding. Some areas had a large increase, and two areasAberdeen and Shetland-showed a decrease. A more detailed analysis by maternity unit, documenting attempts to promote breast feeding, such as participa- tion in the Baby Friendly Hospital Initiative, may allow the effectiveness of health promotion campaigns to be assessed.

The target of $50 \%$ breast feeding at 6 weeks of age by 2005 will not be met unless further health promotion measures are implemented quickly. ${ }^{2}$ The breastfeeding rate dropped by $10 \%$ between 7 days and 6 weeks of age in Scotland in 1995, ${ }^{4}$ and it seems unlikely that the breastfeeding rate at 7 days will reach $50 \%$ in the eight years from 1998 to the end of 2005; at its present rate of change, without further change in maternal age, it will reach only $45.8 \%(42.0 \%+(6.4 \%$ $-2.6 \%)$ ).

Contributors: DMT wrote the paper and is the guarantor. JMM, $\mathrm{AJB}$, and RWAG collected and collated the data.JB and MB analysed the data.

Funding: None.

Competing interests: None declared.

1 Working Group on the Weaning Diet of the Committee on Medical Aspects of Food Policy. Weaning and the weaning diet. London: HMSO, 1994:49.

2 Management Executive. Local breastfeeding targets. Edinburgh: Scottish Office, 1994:1. (MEL (1994) 110.)

3 Ferguson AE, Tappin DM, Girdwood RWA, Kennedy R, Cockburn F. Breast feeding in Scotland. BMJ 1994;308:824-5.

4 Foster K, Lader D, Cheesbrough S. Infant feeding 1995. Results from a survey carried out by the Social Survey Division of ONS on behalf of the UK health departments. London: Stationery Office, 1997.

5 Registrar General for Scotland. Live births and age of mother. Edinburgh: Scottish Office, 1998. (Annual report.)

(Accepted 17 November 2000)

\title{
Analysis of trends in premature mortality by Labour voting in the 1997 general election
}

\author{
Danny Dorling, George Davey Smith, Mary Shaw
}

School of

Geography,

University of Leeds,

Leeds LS2 9JT

Danny Dorling

professor, quantitative

human geography

Department of

Social Medicine,

University of

Bristol, Bristol

BS8 2PR

George Davey

Smith

professor, clinical

epidemiology

School of

Geographical

Sciences, University

of Bristol, Bristol

BS8 1SS

Mary Shaw

senior research fellow

Correspondence to:

G Davey Smith

george.davey-

smith@bristol.ac.uk

BMJ 2001;322:1336-7
Mortality relates to voting patterns within areas: mortality is higher the greater the proportion of the electorate who vote Labour or abstain and the converse is the case with regard to the percentage of the electorate who vote Conservative. ${ }^{1}$ This reflects the socioeconomic characteristics of individuals who vote for these parties, with Labour being identified with the working class and the Conservatives with the middle class. In the 1997 election, Labour was returned to office after 18 years in opposition. The government has released targets for reducing health inequalities and made it clear that such a reduction is a principal policy aim. $^{2}$ These targets may be difficult to meet for two reasons. Firstly, factors influencing inequalities in adult health act from an early age onwards and may not respond rapidly to social change ${ }^{3}$; secondly, there has as yet been no reduction in social inequality (as indexed by income inequality) under the Labour government. ${ }^{4}$ Here we use premature mortality as an indicator of which population groups have fared best under the present government.

\section{Methods and results}

The mortality data are from the Office for National Statistics' digital records of all deaths in England and
Wales and the equivalent records from the General Register Office for Scotland. ${ }^{1}$ The full postcode of the usual residence of the deceased was used to assign each death to one of the 641 parliamentary constituencies to reflect where the deceased usually lived. The death data were provided for single years. Standardised mortality ratios and direct standardised mortality for the age range 0-64 years were calculated using rates for England and Wales.

Because there was no census at the end of the 1990 s, population by age group and sex must be estimated. The Office for National Statistics and the General Register Office produced mid-year population estimates for 1999 and earlier years at the local and unitary authority district levels. To maintain a geographical base consistent with previous studies of Britain's health gap, these district level estimates were interpolated to the electoral ward level and then aggregated to parliamentary constituencies. The interpolation was based on population estimates for 1996, which were available at electoral ward level, and was carried out such that for each age-sex group $\mathrm{W}_{1999}=$ $\mathrm{W}_{1996}+\mathrm{P}_{1996} \times\left(\mathrm{D}_{1999}-\mathrm{D}_{1996}\right)$, where $\mathrm{W}$ and $\mathrm{D}$ are the ward and district level population, $\mathrm{P}$ is the proportion of $\mathrm{D}$ resident in $\mathrm{W}$, and the subscript is the year. The district level population for 1996-9 for each age-sex 
group is from the mid-year estimates of the Office for National Statistics and the General Register Office.

The table shows the standardised mortality ratios for two periods according to the percentage of the vote for Labour in 1997. Standardised mortality ratios rose by $0.8 \%$ reflecting the relatively smaller fall in mortality in Scotland compared with that in England and Wales. The absolute change in mortality nationally fell by $1.8 \%$ when mortality for all of Great Britain was directly standardised by age and sex to the population in England and Wales.

In absolute terms, mortality has improved for all but one of the tenths, although mortality has tended to improve most in areas with the fewest Labour voters. However the absolute mortality of people living in the tenth with the second highest percentage of Labour voters has actually risen over this period. In relative terms, mortality worsened in eight of the tenths, and it worsened most in the areas with higher proportions of Labour voters (with the exception of the tenth with the highest percentage of Labour voters). The correlation between the percentage of the Labour vote and (directly age-sex standardised) absolute change in mortality is $0.13(\mathrm{P}=0.002)$. The equivalent correlation with the change in standardised mortality ratio is also $0.13(\mathrm{P}=0.001)$.

\section{Comment}

Labour's slogan during the 1997 campaign was: "Things can only get better." We have shown that in absolute terms things got better for most areas, but improvement was smaller in areas with a higher percentage of Labour voters. In relative terms things got worse for people in constituencies in which a high proportion of people voted Labour, while things got better for people in constituencies where people generally voted Conservative. This mirrors trends in income inequality, which has increased throughout the period of the Labour government $t^{4}$ the Gini coefficient for the distribution of adjusted post-tax income increased from 38 in 1997-8, to 39 in 1998-9, and 40 in 1999-2000. ${ }^{4}$ Where Labour has improved the life chances of poorer people in Britain they have tended to only just move these people above various "poverty
Standardised mortality ratios and change in these ratios for people aged 0-64 years by percentage of Labour vote in 1997. Parliamentary constituencies were ranked by percentage of Labour vote and divided into 10 equal population groups

\begin{tabular}{|c|c|c|c|c|c|}
\hline \multirow[b]{2}{*}{ Tenth } & \multirow{2}{*}{$\begin{array}{l}\text { Labour vote } \\
\text { (\% of all } \\
1997 \text { voters) }\end{array}$} & \multicolumn{2}{|c|}{ Standardised mortality ratio } & \multirow{2}{*}{$\begin{array}{c}\text { Change } \\
(\%)\end{array}$} & \multirow{2}{*}{$\begin{array}{c}\text { Change in } \\
\text { absolute } \\
\text { mortality (\% }\end{array}$} \\
\hline & & $1995-6$ & $1998-9$ & & \\
\hline First & 72 & 126 & 127 & 1.1 & -2.2 \\
\hline Second & 64 & 120 & 124 & 3.9 & 0.5 \\
\hline Third & 59 & 113 & 115 & 2.3 & -0.6 \\
\hline Fourth & 55 & 108 & 110 & 2.1 & -0.8 \\
\hline Fifth & 51 & 103 & 105 & 2.0 & -0.8 \\
\hline Sixth & 46 & 97 & 98 & 0.3 & -2.8 \\
\hline Seventh & 39 & 89 & 89 & 0.7 & -2.4 \\
\hline Eighth & 30 & 85 & 85 & 0.6 & -1.9 \\
\hline Ninth & 22 & 81 & 81 & -0.4 & -3.4 \\
\hline Tenth & 14 & 86 & 84 & -2.0 & -4.9 \\
\hline Great Britain* & 44 & 101 & 101 & 0.8 & -1.8 \\
\hline
\end{tabular}

*Standardised mortality ratios for Great Britain are 101 because the rates used for standardisation are for England and Wales and rates are higher in Scotland.

lines." ${ }^{, 5}$ It is possible that this trend accounts for the absolute rise in mortality for those younger than age 65 experienced by people living in the tenth with the second highest percentage of Labour voters. Time, and the continued monitoring of the performance of the government through statistics, will tell.

The authors would like to thank Dr Richard Mitchell for his assistance in calculating the population denominators.

Contributors: DD was responsible for data management and statistical analysis and contributed to developing the core ideas. GDS initiated the research and contributed to the discussion of the core ideas. MS coordinated the research and contributed to the statistical analysis. All authors contributed to interpreting the findings and writing the paper. All authors are guarantors. Funding: MS is funded by ESRC Fellowship R000271045. Competing interests: None declared.

1 Davey Smith G, Dorling D. "I'm all right, John": voting patterns and mortality in England and Wales, 1981-92. BMJ 1996;313:1573-7.

2 Department of Health. Health inequalities. www.doh.gov.uk/ healthinequalities/ (accessed 11 May 2001).

3 Davey Smith G, Gunnell D, Ben-Shlomo Y. Life-course approaches to socio-economic differentials in cause-specific adult mortality. In: Leon D, Walt G, eds. Poverty, inequality and health: an international perspective. Oxford: Oxford University Press, 2001:88-124.

4 Lakin C. The effects of taxes and benefits on household income, 1999-2000. Economic Trends 2001;569:35-74

5 Sutherland H, Piachaud D. Reducing child poverty in Britain: an assessment of government policy 1997-2001. The Economic Journal 2001;111:85-101.

(Accepted 23 May 2001)

\section{Not in front of the children}

My father was Irish, from Cork, and came to Britain in the late 1940s. He kept in touch with events at home by way of a subscription to a Cork local newspaper, the Cork Weekly Examiner. Some of my earliest childhood memories are of him sitting in "his" armchair on a Friday night catching up on events from home.

He particularly liked to read the obituary column. "Aud!" he would call to my mother, whose name was Audrey, "Guess who's died?" It was always someone my mother might have met once on her few visits to the Republic of Ireland, but she could never have guessed. As we grew older, this catch phrase was heard more often, reflecting the high cardiovascular death rate in Ireland. We would tease him by mimicking the cry.

As the next generation ages, we find ourselves subconsciously taking on the habits of our parents. These days, when reading the $B M$ J, I turn first to the obituary column. Sometimes I am reassured as I read the advanced ages to which some retired general practitioners live. Other times I am shocked to see entries for doctors in their 20s or, even more discomfortingly, of my own age. Sometimes even names (and faces) from my own time at medical school. However, I have always managed to resist the temptation to call out "Sarah! Guess who's died?"-at least when the children are around.

Peter O'Donnell general practitioner, Sutton, Surrey

We welcome articles of up to 600 words on topics such as A memorable patient, A paper that changed my practice, My most unfortunate mistake, or any other piece conveying instruction, pathos, or humour. If possible the article should be supplied on a disk. Permission is needed from the patient or a relative if an identifiable patient is referred to. We also welcome contributions for "Endpieces," consisting of quotations of up to 80 words (but most are considerably shorter) from any source, ancient or modern, which have appealed to the reader. 